Eye (2018) 32:1147-1148

https://doi.org/10.1038/s41433-017-0007-x

\title{
Current trends of peri-operative cataract cancellations among consultant ophthalmologists in the United Kingdom
}

\author{
Ivan Yeu Ming Yip $D^{1} \cdot$ Emma Samia-Aly $^{1} \cdot$ Akash Raj $^{1}$
}

Received: 16 November 2017 / Accepted: 1 December 2017 / Published online: 1 February 2018

(c) The Royal College of Ophthalmologists 2018

A cancelled cataract operation costs an NHS trust $£ 911$ per patient [1]. Non-monetary costs such as the inconvenience to the patient are also important. In the current climate of efficiency savings and increasing waiting times, it is important to minimise these disruptions. Currently in the UK, The Royal College of Ophthalmology's Cataract Guidelines, 2017 [2] and Local Anaesthesia in Ophthalmic Surgery Guidelines in 2012 [3] state that blood pressure, blood glucose and INR measurements, are important factors to measure and control pre-operatively. The current guidance, however, does not give specific guidance of thresholds due to limited evidence. We were therefore interested to find out current practice to ascertain at which ranges for these parameters would warrant cancellation among consultants and whether local hospital guidelines are in place to standardise practices.

We carried out a 15-question survey (Fig. 1; www. surveymonkey.com) targeted at consultant Ophthalmologists across various trusts in the UK. A total of 304 consultants responded, representing 129 hospitals in the UK, and covering all Royal College of Ophthalmology specified deaneries. $35 \%$ (45) of these hospitals were reported to have a protocol for cataract cancellation in their hospital, but none of the consultants based at the same hospital gave the same parameters. Consultants from 34.9\% (45) hospitals gave conflicting responses as to whether there was a protocol in place.

Of the 304 consultants, $88 \%$ (268) would cancel patients based on blood pressure; the majority $(60 \%, 181)$ gave $180 /$ $100 \mathrm{mmHg}$ as their upper limit.

Eighty-seven percent (265) of consultants cancelled based on INR reading, with $40 \%$ stating they would cancel if patients were above their therapeutic range, while others gave thresholds of $3(35 \%, 108)$ or $4(20 \%, 60)$, or that they would undergo surgery under topical anaesthesia. Eighty

Ivan Yeu Ming Yip

Ivan.yip@nhs.net

Russells Hall Hospital, Dudley, England, UK

\begin{tabular}{|c|c|c|}
\hline Question number & Question & Responses \\
\hline Question 1 & What is your email address? & \\
\hline Question 2 & $\begin{array}{l}\text { Which hospital are you based } \\
\text { in? }\end{array}$ & \\
\hline Question 3 & $\begin{array}{l}\text { Do you have a cancellation } \\
\text { protocol for cataract surgery? }\end{array}$ & $\begin{array}{l}\text { Yes } \\
\text { No }\end{array}$ \\
\hline Question 4 & $\begin{array}{l}\text { Do you cancel patients based } \\
\text { on blood pressure? }\end{array}$ & $\begin{array}{l}\text { Yes } \\
\text { No }\end{array}$ \\
\hline Question 5 & $\begin{array}{l}\text { At which blood pressure } \\
\text { reading, measured on the day } \\
\text { and just prior to surgery, would } \\
\text { you cancel an operation? }\end{array}$ & $\begin{array}{l}<90 / 60 \mathrm{mmHg} \\
<90 / 60 \mathrm{mmHg} \text { with symptoms } \\
<140 / 90 \mathrm{mmHg} \\
\geq 140 / 90 \mathrm{mmHg} \\
\geq 160 / 100 \mathrm{mmHg} \\
\geq 180 / 110 \mathrm{mmHg} \\
\text { Other }\end{array}$ \\
\hline Question 6 & $\begin{array}{l}\text { Do you cancel patients based } \\
\text { on their heart rate? }\end{array}$ & $\begin{array}{l}\text { Yes } \\
\text { No }\end{array}$ \\
\hline Question 7 & $\begin{array}{l}\text { At which heart rate reading, } \\
\text { measured on the day prior to } \\
\text { surgery, would you cancel an } \\
\text { operation? }\end{array}$ & $\begin{array}{l}<45 \text { beats per minute }(\mathrm{bpm}) \\
>85 \mathrm{bpm} \\
>95 \mathrm{bpm} \\
>105 \mathrm{bpm} \\
>115 \mathrm{bpm} \\
>125 \mathrm{bpm} \\
>135 \mathrm{bpm} \\
>145 \mathrm{bpm} \\
>155 \mathrm{bpm} \\
\text { Other (please specify) }\end{array}$ \\
\hline Question 8 & $\begin{array}{l}\text { Do you cancel patients based } \\
\text { on their blood glucose (BM) } \\
\text { level? }\end{array}$ & $\begin{array}{l}\text { Yes } \\
\text { No }\end{array}$ \\
\hline Question 9 & $\begin{array}{l}\text { At which blood glucose reading } \\
\text { (BM), measured on the day of } \\
\text { surgery, would you cancel an } \\
\text { operation? }\end{array}$ & $\begin{array}{l}<4 \\
>10 \\
>15 \\
>25 \\
\text { Other }\end{array}$ \\
\hline Question 10 & $\begin{array}{l}\text { Do you cancel patients based } \\
\text { on their INR? }\end{array}$ & $\begin{array}{l}\text { Yes } \\
\text { No }\end{array}$ \\
\hline Question 11 & $\begin{array}{l}\text { At which INR reading, measured } \\
\text { on the day/day before the } \\
\text { surgery, would you cancel an } \\
\text { operation? }\end{array}$ & $\begin{array}{l}>2 \\
>3 \\
>4 \\
\text { If the INR is more than the } \\
\text { advisable therapeutic range in } \\
\text { cases of metallic prosthetic } \\
\text { implants and multiple DVTs. } \\
\text { Other }\end{array}$ \\
\hline Question 12 & $\begin{array}{l}\text { If the patient is on any of these } \\
\text { anticoagulants (aspirin, } \\
\text { clopidogrel, rivaroxaban, } \\
\text { apixiban, dabigatran, heparin, } \\
\text { low molecular weight heparins) } \\
\text { do you advise them to stop } \\
\text { them prior to surgery? }\end{array}$ & $\begin{array}{l}\text { Yes } \\
\text { No }\end{array}$ \\
\hline Question 13 & $\begin{array}{l}\text { Do you cancel patients if these } \\
\text { anticoagulants (aspirin, } \\
\text { clopidogrel, rivaroxaban, } \\
\text { apixiban, dabigatran, heparin, } \\
\text { low molecular weight heparins) } \\
\text { have not been stopped prior to } \\
\text { surgery? }\end{array}$ & $\begin{array}{l}\text { Yes } \\
\text { No }\end{array}$ \\
\hline Question 14 & $\begin{array}{l}\text { Please specify the number of } \\
\text { days these anticoagulants } \\
\text { (aspirin, clopidogrel, } \\
\text { rivaroxaban, apixiban, } \\
\text { dabigatran, heparin, low } \\
\text { molecular weight heparins) are } \\
\text { stopped before surgery }\end{array}$ & $\begin{array}{l}\text { Same day } \\
2 \text { days } \\
3 \text { days } \\
4 \text { days } \\
5 \text { days } \\
6 \text { days } \\
7 \text { days } \\
\text { Other }\end{array}$ \\
\hline Question 15 & $\begin{array}{l}\text { When do you resume the } \\
\text { anticoagulants if they were } \\
\text { stopped prior to surgery? }\end{array}$ & $\begin{array}{l}\text { Same day } \\
\text { Next day } \\
2 \text { days } \\
3 \text { days } \\
4 \text { days } \\
5 \text { days } \\
6 \text { days } \\
7 \text { days } \\
\text { Other }\end{array}$ \\
\hline
\end{tabular}

Fig. 1 Questionnaire sent out to ophthalmology consultants 
one percent (246) said they do not stop other anticoagulants (including aspirin, clopidogrel, heparins and novel oral antiocoagulants) prior to surgery.

Seventy-eight percent (236) of consultants cancelled based on blood glucose, with 40\% (121) stating above 25 $\mathrm{mmol} / \mathrm{L}$, and $32 \%(97)$ above $15 \mathrm{mmol} / \mathrm{L}$.

Of all the criteria, heart rate gave the most variable response, with only $40 \%$ (123) considering it as a reason for cancellation. There was a huge variety in the upper limit, and symptomatic tachycardia understandably was the most important reason $(14.8 \%, 45)$ rather than the rate.

Consultants across the UK show some consensus on when to cancel patients in relation to blood pressure, blood glucose, INR level and most do not routinely stop other forms of anticoagulation. However, there remains some variability in practice, which is understandable given the lack of specific guidance at present. Studies looking at the influence that these factors may have on cataract surgery are currently limited. A national audit looking at these parameters in relation to complications may be warranted. Our survey highlights a need for more exploration into the immediate pre-operative management of patients.

Funding This work has been presented previously at Royal College of Ophthalmologists Congress, Birmingham, UK, 2016.

\section{Compliance with ethical standards}

Conflict of interest The authors declare that they have no competing interests.

\section{References}

1. 2016-2017 National Prices and National Tariff Workbook. NHS England and Monitor. https://www.gov.uk/government/publications/nhs-national-tariff-payment-system-201617. Last accessed 05/01/2018

2. Cataract surgery guidelines October 2017. Royal College of Ophthalmologists/NICE. https://www.nice.org.uk/guidance/ng77. Last accessed 05/01/2018

3. Local Anaesthesia for Ophthalmic Surgery. Joint guidelines from the Royal College of Anaesthetics and the Royal College of Ophthalmologists. February 2012

\title{
A model of clinical practice: a randomised clinical study evaluating patient satisfaction of nurse-led vs consultant-led intravitreal injection
}

\author{
Ryian Mohamed (i) ${ }^{1} \cdot$ Dhannie Ramcharan ${ }^{2} \cdot$ Sinduya Srikaran $^{2} \cdot$ Evelyn Mensch $^{2}$
}

Received: 26 November 2017 / Accepted: 1 December 2017 / Published online: 5 February 2018

(c) The Royal College of Ophthalmologists 2018

Intravitreal injection treatment (IVT) is the most commonly performed ophthalmic procedure [1]. Evidence now shows that nurse-led IVT achieves comparable safety, visual outcomes and complication rates as consultant-lead care [1-3]. However, patient satisfaction of IVT by non-ophthalmologists, an increasingly common practice [4], has been poorly studied. This is concerning, given the importance of patient

Ryian Mohamed

m0601207@gmail.com

1 General Medicine, Luton and Dunstable Hospital, Luton, UK

2 Department of Ophthalmology, Central Middlesex Hospital, London, UK satisfaction in assessing the quality of medical care and determining levels of treatment viability, therapeutic compliance and malpractice litigation. Our aim was to compare patient satisfaction of nurse-led vs consultant-led IVT.

Patients attending the macular treatment clinic at Central Middlesex Hospital were invited to take part in the study. A total of 61 patients agreed to participate and were subsequently consented and randomised to receive IVT treatment by either the trained clinical nurse $(n=34)$ or by the consultant $(n=27)$ - the 'gold standard'. A modified, validated patient questionnaire (PSQ-18), see Fig. 1, was used to determine six aspects of patient satisfaction. Responses to each item were given a 5-point scale ranging from strongly agree (5 points) to strongly disagree ( 0 points). A painscale, 